\title{
Streptococcus suis: An Underestimated Emerging Pathogen in Hungary?
}

\author{
Márió Gajdács ${ }^{1,2, *(\mathbb{D})}$, Anita Németh ${ }^{3}$, Márta Knausz ${ }^{3} \mathbb{D}$, Ibrahim Barrak ${ }^{4}$, Anette Stájer ${ }^{5}$ (D), \\ Gyula Mestyán ${ }^{6}$, Szilvia Melegh ${ }^{6}$, Adrienn Nyul ${ }^{6}$, Ákos Tóth ${ }^{7}$, Zsuzsanna Ágoston ${ }^{8}$ and \\ Edit Urbán ${ }^{9}$
}

1 Department of Pharmacodynamics and Biopharmacy, Faculty of Pharmacy, University of Szeged, Eötvös utca 6., 6720 Szeged, Hungary

2 Institute of Medical Microbiology, Faculty of Medicine, Semmelweis University, Nagyvárad tér 4., 1089 Budapest, Hungary

3 Microbiology Laboratory, Petz Aladár County Teaching Hospital, Vasvári Pál utca 2-4., 9023 Győr, Hungary; anita8909@hotmail.com (A.N.); knauszm@petz.gyor.hu (M.K.)

4 Department of Prosthodontics, Faculty of Dentistry, University of Szeged, Tiszta Lajos körút 62-64., 6720 Szeged, Hungary; barrakibrahim@gmail.com

5 Department of Periodontology, Faculty of Dentistry, University of Szeged, Tiszta Lajos körút 62-64, 6720 Szeged, Hungary; stajeranette@gmail.com

6 Department of Medical Microbiology and Immunology, Faculty of Medicine, University of Pécs, Szigeti út 12., 7624 Pécs, Hungary; mestyan.gyula@pte.hu (G.M.); melegh.szilvia@yahoo.co.uk (S.M.); nyul.adrienn@pte.hu (A.N.)

7 Department of Bacteriology, Mycology and Parasitology, National Public Health Center, Albert Flórián út 2-6., 1097 Budapest, Hungary; toth.akos@nnk.gov.hu

8 Department of Anaesthesiology and Intensive Therapy, Faculty of Medicine, University of Szeged, Semmelweis utca 6., 6725 Szeged, Hungary; agoston.zsuzsanna@med.u-szeged.hu

9 Institute of Translational Medicine, Faculty of Medicine, University of Pécs, Szigeti út 12., 7624 Pécs, Hungary; zsoldiedit25@gmail.com

* Correspondence: gajdacs.mario@pharm.u-szeged.hu or mariopharma92@gmail.com; Tel.: +36-62-341-330

Received: 24 July 2020; Accepted: 21 August 2020; Published: 24 August 2020

\begin{abstract}
Streptococcus suis (S. suis) is an emerging zoonotic pathogen, demonstrated as an etiological agent in human infections in increasing frequency, including diseases like purulent meningitis, sepsis, uveitis-endophtalmitis and arthritis. Due to the increased availability and utility of novel diagnostic technologies in clinical microbiology, more studies have been published on the epidemiology of S. suis, both in veterinary and human medicine; however, there are no comprehensive data available regarding human S. suis infections from East-Central European countries. As a part of our study, data were collected from the National Bacteriological Surveillance (NBS) system on patients who had at least one positive microbiological result for S. suis, corresponding to an 18-year study period (2002-2019). $n=74$ S. suis strains were isolated from invasive human infections, corresponding to 34 patients. The number of affected patients was $1.89 \pm 1.53$ year (range: $0-5$ ). Most isolates originated from blood culture $(63.5 \%)$ and cerebrospinal fluid (18.9\%) samples. Additionally, we present detailed documentation of three instructive cases from three regions of the country and with three distinctly different outcomes. Hungary has traditional agriculture, the significant portion of which includes the production and consumption of pork meat, with characteristic preparation and consumption customs and unfavorable epidemiological characteristics (alcohol consumption, prevalence of malignant diseases or diabetes), which have all been described as important predisposing factors for the development of serious infections. Clinicians and microbiologist need to be vigilant even in nonendemic areas, especially if the patients have a history of occupational hazards or having close contact with infected pigs.
\end{abstract}


Keywords: Streptococcus suis; zoonosis; emerging infection; surveillance; meningitis; sepsis; hearing loss; agriculture; Hungary

\section{Introduction}

Streptococcus suis (S. suis) is an emerging zoonotic pathogen, which has been demonstrated as an etiological agent in human infections in increasing frequency [1,2]. The clinical presentations of these-often serious or life-threatening-infections may be wide-ranging, including syndromes such as purulent meningitis, sepsis, streptococcal toxic shock-like syndrome (STSLS), uveitis-endophthalmitis and arthritis; nevertheless, S. suis has also been described as an opportunistic pathogen of lower respiratory tract infections (e.g., pneumonia) [3-5]. In recent years, due to the increased availability and utility of novel diagnostic technologies and molecular biological methods both in veterinary and human clinical microbiology, more studies have been published on this zoonotic infectious entity, including the epidemiology of human infections and the virulence factors of this pathogen [6,7]. The bacterium has been described as a colonizing agent in the upper respiratory, gastrointestinal tract, and genital organs of various animals (pigs, ruminants, cats, dogs, horses and other wild animals). S. suis was first reported in 1954 by veterinarians after outbreaks of septicemia and/or meningitis and purulent arthritis occurred among piglets [8-10]. Fourteen years later, some human S. suis cases were first described in Denmark [11]. So far, over 1600 human cases have been reported in the literature worldwide, although this infection is probably severely underdiagnosed [1,2,12]. Subsequently, the number of human $S$. suis cases reported has increased over the past few years, with the highest prevalence rate in Southeast Asia, where there is a high rate of pig meat consumption: the majority of these infections originated from Thailand $(\sim 36 \%)$, Vietnam $(\sim 30 \%)$ and China $(\sim 22 \%)$; therefore, Thailand and Vietnam have the highest disease prevalence stratum globally, with estimated 0.82 and 0.54 cases/100,000 population, respectively $[13,14]$. In contrast, the prevalence in Western European countries ranges between $0.01-0.10$ cases/100,000 population (with highest prevalence in the Netherlands and the UK) $[1,4]$. The epidemiological situation in Australasia is similar to the one on the European continent, while the Americas and Japan has reported the lowest prevalence of human $S$. suis cases $(<1 \%$ of global cases) [1-4]. The clinical relevance of these invasive infections must not be underestimated; based on the results of a meta-analysis, the mortality rate associated with these infections is $12.8 \%$ (confidence interval: $9.0 \%-18.0 \%$ ), with notable geographical differences observed among geographical regions (Asia: up to $26 \%$, Western countries: $2-4 \%$ ); in addition, almost half of the patients experience some kind of neurological sequelae after recovery [4].

These bacteria are facultatively anaerobic Gram-positive, ovoid or coccal bacilli, with sizes on average between 1.0 to $1.5 \mu \mathrm{m}$, appearing in pairs, short chains or as single bacteria [15]. The bacterial species is genetically and phenotypically very heterogeneous, which were earlier classified into the Streptococcus Lancefield groups R, S, and T [16]. Currently, S. suis is classified within the family Streptococcaceae, order Lactobacillales, phylum Firmicutes [17]. The bacterial virulence-associated factors may be classified into the following sub-groups (of note, some genes probably may be classified into more than one categories due to their dual characteristics): (i) surface/secreted elements; (ii) protease enzymes; (iii) transcription factors/regulatory systems and (iv) other virulence determinants (transporters/secretion systems) [18]. The list of confirmed and putative virulence factors is extensive, but the most prominent and best-characterized virulence factors of clinical S. suis strains are surface and secreted elements: capsular polysaccharides, extracellular factor (EF; epf), muramidase-released protein (MRP; mrp) and a 38-kDa surface protein, suilysin (SLY) [19-22]. S. suis isolates are included a complex population consisting of heterogeneous strains and they may be classified into 35 serotypes (1-34, $1 / 2$ ) to date, based on the principal virulence factor, the capsular polysaccharide antigen (CPS) [23,24]. Human S. suis cases are reported to be mainly due to serotype 2 (SS2) (24.3-74.7\%) and 14 (2.0-13.0\%), with both serotypes being equally implicated in cases of meningitis (50-70\%) and sepsis (20-25\%) [4,25]. 
SS2 is believed to be the most virulent type, with a polymorphic mosaic genome, which is associated with a higher virulence and is frequently isolated from humans affected by these infections [26]. The occurrence of serotype 14 infections was sporadically reported in Northern Thailand, Vietnam and case reports were also described in the UK, France, Australia, and Canada [27,28]. In constrast, serotype 9 is one of the most common (19.4-61.0\%) in the pigs of some Western European countries [29]. Infections caused by serotypes $4,5,8,9,11,12,13,16,21,24,31$ and species with untypeable serotypes are considered to be rare (0-2.7\%) - only sporadic cases were reported [4,30-35]. S. suis isolates causing streptococcal toxic shock syndrome (STSS) and high mortality rates were associated with the presence of a pathogenicity island (89K PAI), most commonly seen in large Chinese outbreaks [36].

There are some typical risk factors for acquiring $S$. suis infections such as raw (or uncooked) pork consumption, direct exposure to pigs or pork, workplace exposure in several professions (e.g., butchers, slaughterhouse workers, hunters, retail workers in butcheries), excessive consumption of alcohol, skin injuries (especially during handling pig or pork), male gender and some underlying diseases contributing to immuno-compromised conditions [37,38]. Most patients, who were infected by serotypes other than SS2, had liver cirrhosis [30,34] or other pre-existing immunosuppressive states [39]. In addition, as previously reported for invasive Group B Streptococcus infections, alcoholism, diabetes mellitus, splenectomy and malignancies have been suggested as important predisposing factors for the development of rapid and fatal S. suis infections [40]. In humans, the intestinal route of infection seems to be an important port of entry, after consumption of fresh/raw contaminated pork meat (e.g., in some Southeast Asian countries) [41]. In fact, the epidemiology of human infections may be significantly affected by the cultural differences and eating habits between the Asian and the European/American regions, while this also raises concerns regarding imported cases due to increasing levels of tourism towards Asia [1-5]. Apart from the handling or ingestion of pork meat, direct contact with the mucous membranes of pets (cats, dogs), livestock (horses, ruminants) and wild animals (deer, wild boar) may also be an important source of infection [37,38]. To date, human-to-human transmission has not been demonstrated to occur. Nevertheless, the transmission of bacteria through skin abrasions was also believed to be an important route of infection, altough skin injuries in patients during exposure or before infection were noted only in some studies [42]. Earlier studies suggest that sometimes humans could be healthy carriers of $S$. suis as well [43-45]. Encapsulated S. suis strains are highly invasive pathogens; after penetration of host mucosal barriers, these bacteria may reach and survive in the blood cells and they may subsequently invade different organs, such as liver, kidney, spleen, lung and even the heart [46]. Pathogenic strains are able to cross the brain microvascular endothelial cells (BMECs) and/or the epithelial cells of the choroid plexus at the blood-brain barrier (BBB) and/or the blood-cerebrospinal fluid barrier to gain access to the central nervous system (CNS) [43,47-49]. After an incubation period that ranges from a few hours to a few days in humans, S. suis infections result in meningitis, sepsis, pneumonia, endocarditis or peritonitis $[1,2,12,43,50,51]$. In addition, peracute infections with shock and a high mortality rate have been described, particularly in the case of streptococcal toxic shock-like syndrome (STSLS) [52].

Around $8-10 \%$ of cases worldwide were reported from the European continent; however, to date, there are no comprehensive epidemiological data available in the literature regarding human $S$. suis infections from East-Central European countries $[4,15,53]$. The aim of our present study was to report on the emergence and clinical manifestations of $S$. suis infections in Hungary over a long surveillance period-using data from the national bacteriological database-in addition to illustrating the various possible clinical outcomes of human S. suis infections through the description of instructive cases from various Hungarian clinical centers. 


\section{Materials and Methods}

\subsection{Study Site and Population}

Hungary is a medium-sized, landlocked country in East-Central Europe, with a total area of $93,030 \mathrm{~km}^{2}$ and a population of 9,772,756 persons (estimated from the most recent census data; population density: 105.1/ $\mathrm{km}^{2}$ ) [54]. The area of Hungary may be divided into 7 regions or 19 counties (in addition to the capital of Budapest) for administrative purposes. Based on Organisation for Economic Co-operation and Development (OECD) guidelines, Hungary is a high-income country (with the 54th largest global economy based on nominal gross domestic product (GDP) and 45th highest Human Development Index (HDI)) [55]. The average life expectancy in Hungary is 72.4 years for males and 79.0 years for females. Hungary currently has 165 hospitals, with 70 beds and 40.9 medical doctors per 10,000 people [56].

Among national characteristics pertaining to risk factors of S. suis infections, $28.65 \%$ of the population lives in rural areas and around $5 \%$ of the population works in full-time agriculture [56,57]. According to the census data, $52.4 \%$ of the population is female [54]. Hungary has one of the highest rates of people with type II diabetes, very high rates of smoking prevalence and one of the highest rates of morbidity due to malignant diseases in Europe [54-57]. The total per capita consumption of alcohol is estimated to be $11.4 \mathrm{~L} /$ year, which is much higher than the worldwide average [ $6 \mathrm{~L} /$ year], based on WHO criteria [58]. Meat consumption is estimated to be $65.04 \mathrm{~kg} /$ person annually (moderate), out of which $\sim 25 \mathrm{~kg} /$ person (i.e., $38.5 \%$ ) is pork meat per capita [59]; however, this ratio was over $50 \%$ during the period between 2000 and 2010. In an attempt to boost domestic pork production and consumption, the Hungarian government has cut the value-added tax (VAT; from 27\% to 5\%) on pork offal and related products [60].

\subsection{Data Collection}

As a part of our study, data were collected from the Subcommittee on Gram-positive bacteria of the National Bacteriological Surveillance (NBS) system on patients who had at least one positive microbiological result for $S$. suis in a hospital (including intensive care units and departments of traumatology, surgery, pediatrics, dermatology, ophthalmology, obstetrics and gynecology, otorhinolaryngology, and head and neck surgery) in Hungary, between 1 January 2002 and 31 December 2019 (18-year-long period) [61]. The following anonymized data were exclusively collected during the study: age at sample submission, gender, place of residence, type of sample(s) submitted for microbiological analysis, results of microbiological analyses, and antimicrobial susceptibility testing.

\subsection{Bacterial Identification, Antibiotic Susceptibility-Testing}

Sample processing and microbial identification in the respective microbiology laboratories were carried out according to guidelines for routine clinical bacteriology. Cerebrospinal fluid samples and blood samples were taken for both clinical chemistry and microbiology. Blood culture samples for microbiological analysis were inoculated into blood culture bottles and incubated in automated blood culture systems. If the blood culture instrument reported a positive result, samples were inoculated onto relevant agar media. In case of cerebrospinal fluid samples, enrichment broth media were also used in addition to agar media. Latex agglutination-based rapid tests-aiming to identify the main pathogens of bacterial meningitis from the cerebrospinal fluid-were also performed. After 2013, several tertiary-care hospitals and specialized-care centers have introduced matrix-assisted laser desorption/ionization time-of-flight mass spectrometry (MALDI-TOF MS) into their diagnostic workflow [62,63].

Antimicrobial susceptibility testing was performed by the disk diffusion method for penicillin (from which, susceptibility to other $\beta$-lactams may be inferred), erythromycin, clindamycin, moxifloxacin, tetracycline, and vancomycin. Inducible clindamycin resistance was detected using the D-test and these strains were also reported as resistant [64]. The results were interpreted following the breakpoints 
for viridans streptococci approved by the European Committee on Antimicrobial Susceptibility Testing (EUCAST) for penicillin and other $\beta$-lactam antibiotics, clindamycin and vancomycin, Clinical and Laboratory Standards Institute (CLSI) guidelines were used for erythromycin and tetracycline, while in the case of moxifloxacin, S. pneumoniae breakpoints were used [4,15]. Intermediate results were grouped with and reported as resistant.

\subsection{Statistical Analysis}

Due to the low number of relevant isolates, only descriptive statistical analyses were performed. Categorical variables were summarized by frequencies and percentages, while continuous data were presented as mean \pm standard deviation (SD) and counts or percentages (\%). All statistical analyses were performed using Statistical Package for Social Science (SPSS) software (IBM SPSS Statistics for Windows 24.0, IBM Corp., Armonk, NY, USA).

\subsection{Ethical Statement}

Data collection on anonymized patient affected by S. suis infections was in accordance with ethical standards at the institutional and/or national research committees and with the 1964 Helsinki Declaration and its later amendments.

\section{Results}

\subsection{Epidemiology and Antibiotic Susceptibility of S. suis Infections in Hungary}

During the 18-year study period (2002-2019) $n=74$ S. suis strains were isolated from invasive human infections in Hungarian hospitals (based on reports to the NBS), corresponding to 34 patients. The number of affected patients was $1.89 \pm 1.53$ /year (range: $0-5$ ), which was consistent throughout the study period; however, there were zero cases in 2007 and 2010, while peaks of $n=5$ cases were seen in 2014 and 2018, respectively. The temporal distribution of S. suis infections is presented in Figure 1, while the spatial distribution of cases in Hungary is shown in Figure 2. The number of cases was almost double as high in the second half (2011-2019) of the study period (12 vs. 22). The average incidence of $S$. suis infections was $0.35 / 100,000$ persons. The median age of affected patients in 57 years (range: $21-91$ years), while 20 out of 34 patients (58.8\%; male-to-female ratio: 1.43 ) were males. Among the indications listed for sample submissions, the most common was meningitis $(n=36,48.6 \%)$, followed by fever $(n=18,24.4 \%)$, sepsis $(n=10,13.5 \%)$, and other infectious processes $(n=10,13.5 \%)$. Immuno-suppression was verified in only 5 out of 34 patients, while a known history of contact with pigs or other companion animals was noted only in 4 out of 34 patients.

Out of the $n=74$ samples positive for $S$. suis, $n=47(63.5 \%)$ were blood culture samples, $n=14$ $(18.9 \%)$ were cerebrospinal fluid samples, $n=6(8.1 \%)$ were wound samples, while $n=7$ (one abscess sample, one bile samples, one inner ear aspirate, two pus samples and two intra-abdominal fluid samples; $9.5 \%$ ) were others. The incubation period usually ranged between $<1$ to 4.2 days. In case of $n=7$ patients, $S$. suis was simultaneously present in both their blood culture and cerebrospinal fluid samples. During the analysis of susceptibility-testing results, only the first isolate per patient was included: all the respective isolates were uniformly susceptible to $\beta$-lactam antibiotics and vancomycin (34/34), while 14/34 of isolates were resistant to erythromycin and clindamycin, 10/34 of isolates were resistant to moxifloxacin and 9/34 were resistant to tetracycline. Data on S. suis serotypes were only available in the in case of the most recent 11 cases (including the three cases described in detail below): $n=10$ were the SS2, while $n=1$ was the SS14 serotype. 


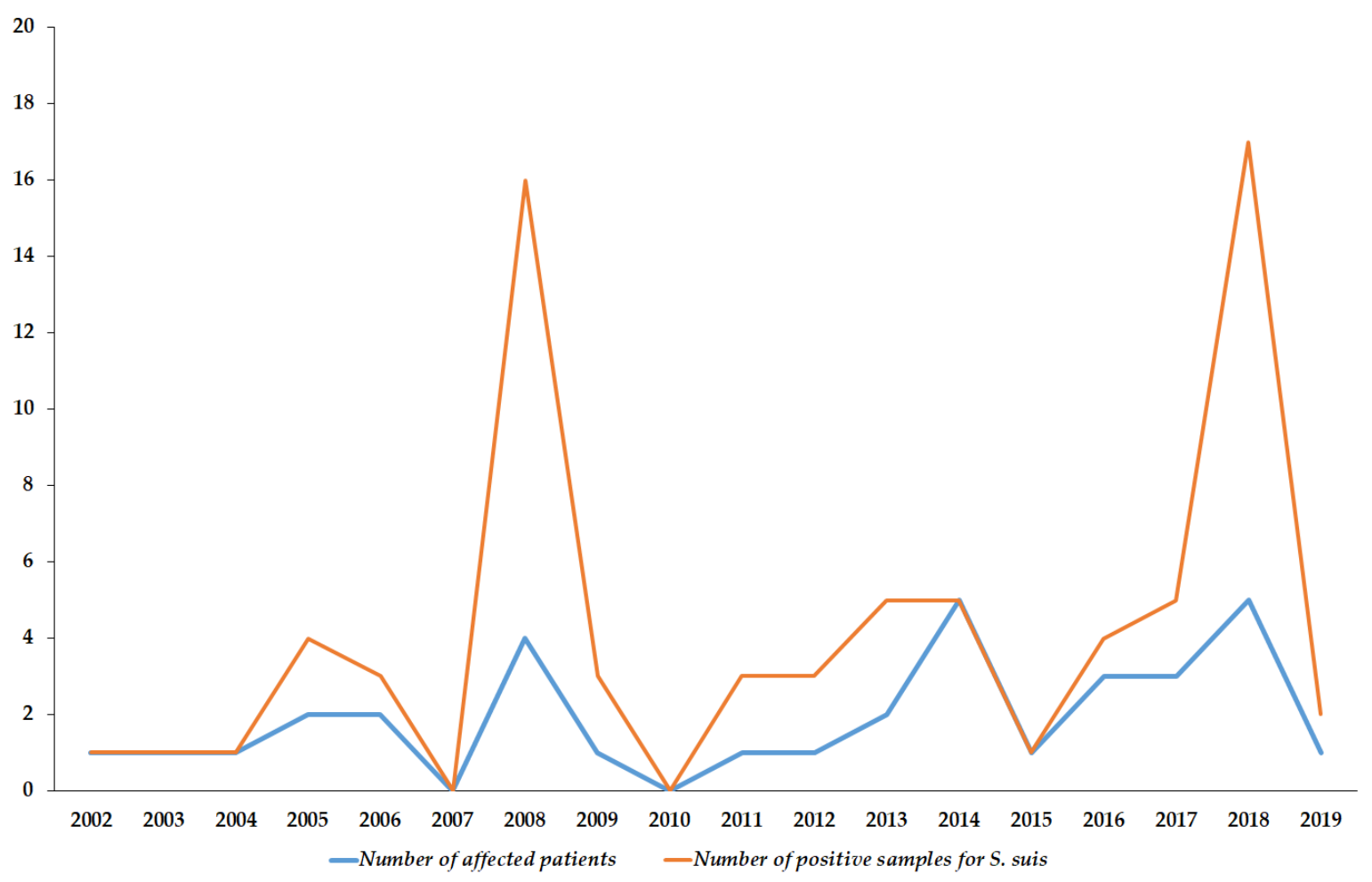

Figure 1. Secular trends of the isolation of S. suis in Hungary (2002-2019).

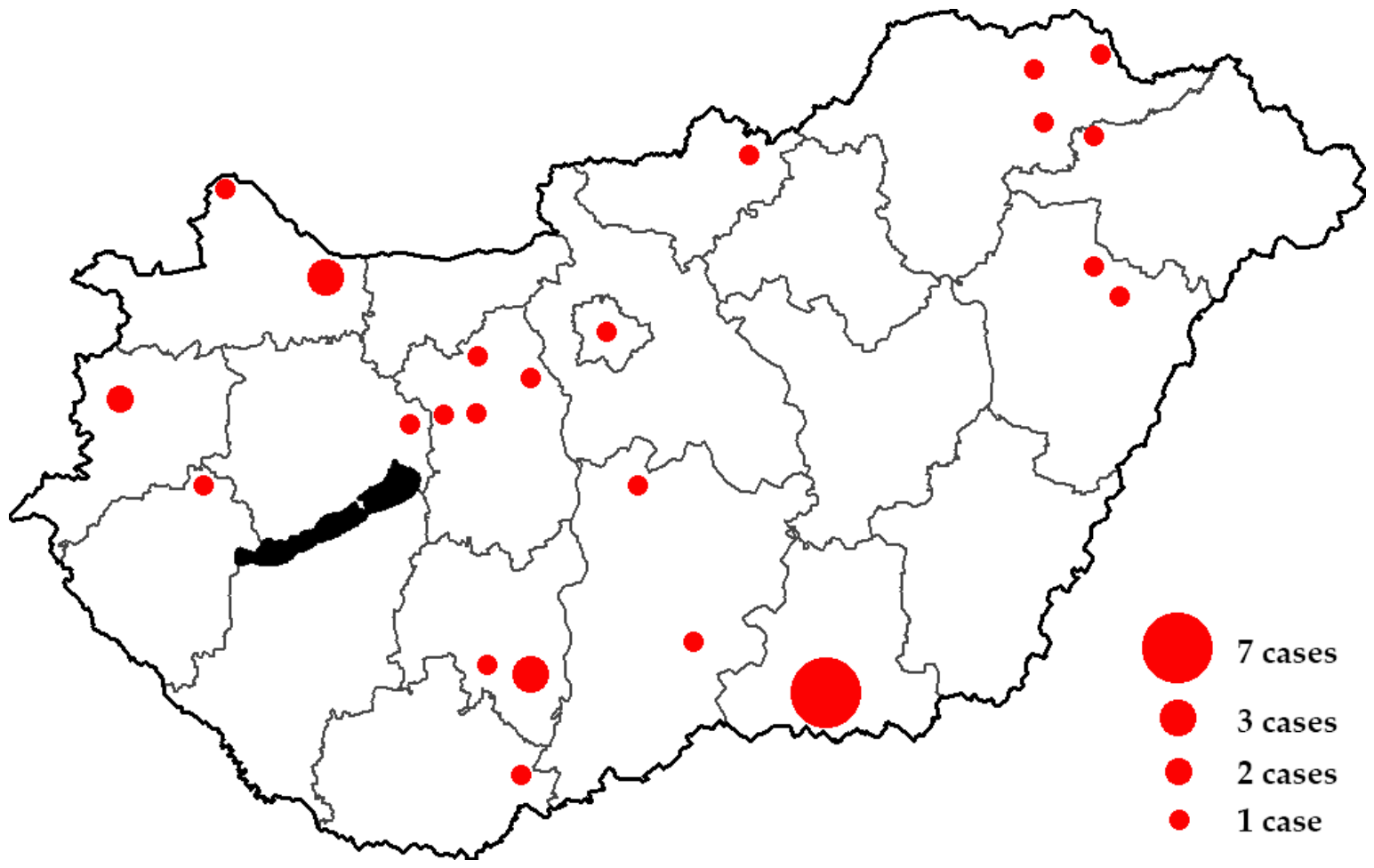

Figure 2. Spatial distribution of human S. suis clinical cases in Hungary (2002-2019).

\subsection{Description of Three Distinct Cases in Hungary with Remarkably Different Clinical Outcomes}

To further illustrate the importance of $S$. suis infections in various clinical situations, herein we present detailed documentation of three instructive cases from the material of the last two years, from three regions of the country and with three distinctly different outcomes for each affected patient. 


\subsubsection{Case 1}

At the Petz Aladár County Teaching Hospital in Győr in January 2018 -in the midst of an influenza epidemic - a male patient presented with symptoms of purulent meningitis, whose brief medical history is described below: the 48-year-old male patient was admitted to the Emergency Department (ED) after being transferred to the hospital by the National Ambulance Service from the patient's place of residence. The patient was admitted due to a headache; high fever $\left(41^{\circ} \mathrm{C}\right)$ and myalgia, which presented two days before; and vomiting, diarrhea and aphasia, which presented one day before hospital admission. The past medical history of the patient was unremarkable. The vital signs of the patient were the following: $156 / 104 \mathrm{mmHg}$, pulse: $117 / \mathrm{min}$, body temperature: $37.3^{\circ} \mathrm{C}$ (due to administration of antipyretic medication at home), oxygen saturation: $98 \%$. Upon physical examination, the patient was alert but disoriented, meningeal excitatory signs (Kernig, Brudzinski) were positive. On admission, other abnormalities were not detected; a rash, bleeding, swollen or painful joints were not seen. Among laboratory parameters, the WBC count of $25.6 \mathrm{G} / \mathrm{L}$ and the CRP-levels of $162.4 \mathrm{mg} / \mathrm{L}$ were of interest. No abnormalities were seen on the chest X-ray or the head CT. Subsequently, samples were taken for laboratory analysis: blood samples and cerebrospinal fluid were sent to the Department of Clinical Chemistry, while two sets of blood culture bottles and a cerebrospinal fluid sample was sent to the microbiology department for culture. During the lumbar puncture, opalescent cerebrospinal fluid was observed, flowing at medium pressure. The result of the examination of the cerebrospinal fluid at the Department of Clinical Chemistry was the following: cell count: 750, protein: $3.5 \mathrm{~g} / \mathrm{L}$, glucose: $1.2 \mathrm{mmol} / \mathrm{L}$. Rapid tests from the cerebrospinal fluid, aiming to identify the main pathogens of bacterial meningitis (S. pneumoniae, S. agalactiae, Haemophilus influenzae, Neisseria meningitidis A, C, Y, W135, N. meningitidis B, E. coli K1) showed a negative result. A Gram-stained smear from the cerebrospinal fluid was observed under a microscope: 20-30 granulocytes and Gram-positive, spear-shaped diplococci were observed per field of view. Based on the microscopic image, the pathogenic role of $S$. pneumoniae was suspected, but this was not confirmed by the rapid latex agglutination test. Following the administration of dexamethazone, empiric antibiotic therapy (ceftriaxone, ampicillin) was initiated at the ED, according to the protocol for the treatment of community-acquired purulent meningitis, and then the patient was placed in the Infectious Disease Ward. On the second day of treatment, an $\alpha$-hemolytic Streptococcus was cultured from both the blood culture samples and the cerebrospinal fluid. Identification was carried out using an ID32 Strep (bioMérieux, Marcy-l'Étoile, France) semi-automatic identification system; the pathogen has been successfully identified as $S$. suis. For verification purposes, the isolate was sent to the National Institute of Public Health; the original identification was also verified by a MALDI-TOF MS system.

Antibiotic susceptibility testing of the isolate was carried out: the isolate was shown to be susceptible to penicillin and ceftriaxone. Armed with susceptibility-results, the empiric ampicillintherapy was suspended and ceftriaxone monotherapy was initiated which lasted for 14 days. Consultation with a cardiologist has excluded the possibility of endocarditis. Audiological examinations were not carried out, as the patient did not have such symptoms. After the administration of the antibiotic therapy, the patient's complaints have disappeared, the laboratory parameters regressed, and the control microbiological examinations (blood cultures, cerebrospinal fluids) were negative. The isolate was found to be the SS2 serotype. No sequelae were observed either after discharging of the patient or after follow-up examinations one month later. Given the role of S. suis in zoonosis, a detailed heteroanamnesis revealed that the patient kept Mangalica (Mangalitsa or Mangalitza), a Hungarian breed of domestic pigs, on his family farm and one of his hobbies included hunting. Two days before he fell ill, he hunted down a wild boar and processed it in his own home.

\subsubsection{Case 2}

A 37-year old male patient-who was employed as a waste collector-was transferred from the ED of the local hospital in Mohács to the Department of Neurology of the University of Pécs, due to progressive loss of consciousness, headache, fever, numbness of the right arm and primary progressive 
aphasia. The patient's past medical history was unremarkable, apart from known diagnoses of ulcus duodeni and hypertension. Based on the reports of the ambulance staff, the socio-economic status of the patient was low (in their apartment, a high degree of clutter and garbage was seen). The patient showed meningeal excitatory signs (Kernig, Brudzinski) and presented with neck stiffness; thus, blood cultures and cerebrospinal fluid samples were taken for microbiological analysis. During laboratory analysis, inflammatory markers (C-reactive protein: $200 \mathrm{mg} / \mathrm{L}, \mathrm{WBC}: 18,700 / \mu \mathrm{L}$ ) were elevated and $60,000-70,000 / \mathrm{mm}^{3}$ of granulocytes were counted in the cerebrospinal fluid. Results of the latex-agglutination "meningitis" rapid tests were negative. Both samples types were positive for an optochin-resistant, $\alpha$-hemolytic Streptococcus, which was subsequently identified as Aerococcus viridans by an API 20 Strep Kit (bioMérieux, Marcy-l'Étoile, France). As the patient did not have any underlying illnesses that would point to the infectious role of A. viridans, the bacterial isolates were sent to two partnering laboratories for further processing. In the Bay Zoltán Nonprofit Ltd. for Applied Research (Budapest, Hungary), MALDI-TOF MS analysis was carried out, which has identified the strain as $S$. suis with a reliable log score (>2.300). In the Department of Epidemiology and Microbiology, Faculty of Veterinary Medicine, Szent István University (Budapest, Hungary), two methods were utilized; namely, the Biolog MicroStation ${ }^{\mathrm{TM}}$ ID System (Hayward, CA, United States), and 16S rRNA gene sequencing (Illumina, San Diego, CA, United States). While the former method was unable to identify the isolate in question, 16S rRNA gene sequencing has found the highest (99\%) match with the sequences of $S$. suis. The isolate was the SS2 serotype of S. suis. After successful identification, antibiotic susceptibility testing was carried out: the isolate was susceptible to $\beta$-lactam antibiotics, therefore the empirical ceftriaxone therapy was continued and the patient's condition improved rapidly. The patient was discharged after 14 from his initial admittance to the ED. The patient denied any sort of contact with pigs or other companion animals. During follow-up examinations, the patient was assessed at the Department of Oto-Rhino-Laryngology, where the patient reported deafness on the right side, and perceptional hearing loss on the left side. As a sequela, right-sided partial hearing loss was observed by the patient, which has persisted in the subsequent follow-up examinations as well.

\subsubsection{Case 3}

A 34-year-old male patient was admitted to the ED of the Albert Szent-Györgyi Clinical Center in Szeged, due to high fever $\left(39.9^{\circ} \mathrm{C}\right)$ and unconsciousness. In his past medical history, obesity $(\mathrm{BMI}>30)$ and splenectomy was recorded 10 years ago due to a motorway accident. The patient was employed as a butcher in a local meatpacking plant, where he was reportedly injured on his hand by a sharp fragment of a pork bone, which occurred one day before admission. On arrival, the obese (BMI > 30) patient presented with no neck stiffness or meningism, nor peripheral stigmata of infective endocarditis. The patient had a high fever, chills, abdominal pain and watery diarrhea at his home; family members found the unconscious patient on the bathroom floor. XBLS (Extended Basic Life Support) and later ALS (Advanced Life Support) were started because of circulatory and respiratory failure. The patient was intubated and epinephrine was administered, which was followed by the return of spontaneous circulation. Cranial and abdominal CT scans and pulmonary angiography were carried out to rule out various pathologies. Cranial CT showed right-sided, multiple, acute ischemic lesions. On admission to the ICU, the patient presented with severe hypotension, sinus tachycardia and high fever, even after the administration of intravenous dopamine. Despite positive end-expiratory pressure (PEEP) appropriate oxygenation could not be achieved and respiratory and metabolic acidosis, severe hypoglycemia and hypokalemia were noted. Supportive therapy $\left(\mathrm{K}^{+}\right.$-substitution, ventilation support and glucose) and subsequent high-dose vasopressor therapy only led to minor improvements. Duplicate blood cultures, urine samples, feces and sera for serology were taken and sent with urgency to the microbiology laboratory. Leukocyte cell count and C-reactive protein were $17.0 \times 10^{9} / \mathrm{L}$ and $0.65 \mathrm{mg} / \mathrm{dL}$, respectively. Laboratory results confirmed disseminated intravascular coagulation (DIC; suspected by bleeding from puncture sites and emergence of petechiae) and acute kidney and liver failure. The patient died 
from complications (DIC, multi-organ failure and acute respiratory distress syndrome) within $12 \mathrm{~h}$ of hospital admission.

Post-mortem examination verified DIC and multiple organ damage, microthrombosis and necrosis, predominantly in the lungs, liver, kidneys. The results of serology and microbiological analyses were received after the patient had already passed away. S. suis was detected in the blood culture samples previously submitted (time to positivity: 1 and $4 \mathrm{~h}$, respectively), while viral serology only revealed a past EBV infection. S. suis was identified by MALDI-TOF MS (Bruker Daltonics, Billerica, MA, USA), with a reliable log score (>2.300). Identification was also complemented by $16 \mathrm{~S}$ rRNA gene sequencing. Sequencing of the $16 S$ rRNA gene confirmed that the strain belonged to the species S. suis with $99 \%$ nucleotide identity compared with GenBank accession no. NR036918, AF009487 and AM946016. The isolate was found to be the SS2 serotype. The strain was susceptible to $\beta$-lactam antibiotics and resistant to clindamycin, erythromycin and tetracycline. Resistance-determinants were verified using a PCR assay, indicating that our isolate with the tet $(Q)$ and $\operatorname{erm}(B)$ genes.

\section{Discussion}

S. suis is a Gram-positive, facultative anaerobic bacterium, which is commonly found in the microbiota of pigs and they may also be found in other animals to a lesser extent [65]. The piglets may be healthy carriers or they may be afflicted by the presence of these pathogens. S. suis is normally found in the upper respiratory tract of pigs, mostly in the tonsils (tonsil carriage rate in piglets aged 4-6 months is around 32-50\%), nasopharynx, gastro-intestinal, genital and alimentary tracts [66,67]. Transmission among pigs is generally the respiratory system in the form of direct nose-to-nose contact (horizontal transmission); however, vertical transmission through the genital tract during farrowing is also possible [68]. Susceptible animals may suffer from similar disease manifestations (meningitis, septicemia, pneumonia, endocarditis, or polyarthritis) as their human counterparts and the pathogenesis of the disease is also thought to be very similar [69]. Therefore, S. suis infections in animals are an important economic burden to the livestock-breeding industry. There are continent-wide programs aimed at the prevention of $S$. suis disease in livestock [70].

Infections caused by $S$. suis — which are mainly related to pigs—are causing zoonotic diseases of increasing frequency worldwide. The first human case was reported in 1968, with sporadic cases occurring worldwide in subsequent years. Nevertheless, the true significance of this zoonotic pathogen has been demonstrated after multiple outbreaks in Asia (e.g., China, Vietnam) associated with S. suis were reported [71]. Exporting pork goods (containing multiple S. suis serotypes) may lead to the development of more virulent strains through recombination or the exchange of mobile genetic elements between the local and foreign isolates [72]. A breach in the integrity of the skin is postulated to be one of the main routes of infection in Western countries; however, the precise route of transmission is not always identified [73]. Some cases have been linked to accidental inhalation of infected aerosols from infected carcasses, though $S$. suis is also found in faces and fomites of infected animals $[1,2,15,73]$. The prevalence of $S$. suis infections in humans has shown a notable increase in the last decade, with highest prevalence values in countries with a high pig density (i.e., Southeast Asia) [74]. There is a wide clinical variation in the presentation of $S$. suis infections in humans, but meningitis and sepsis are the most common and serious clinical manifestations of $S$. suis infections; these pathologies are usually accompanied with hearing loss in the surviving patients (which was also demonstrated in our Case 2) [75-77]. According to animal experiments, the human pathomechanism of hearing loss is likely from the invasion of $S$. suis to the perilymph, via the cochlear aqueduct, resulting in suppurative labyrinthitis [78]. This concomitant morbidity warrants the need of close monitoring and early adequate care in meningitis patients; in addition, the invasive nature of $S$. suis serotype 2 may have an important role in the development of these sequelae. The polysaccharide capsule containing sialic acid feature makes the organism highly invasive in entering the bloodstream and penetrating the blood-brain barrier [79]. One specific feature suggested for the European S. suis isolates is their predilection to the meninges and their frequent involvement in the etiology of purulent meningitis [80]. In a report 
published by Mancini et al., the first fatal human case of S. suis streptococcal toxic shock syndrome (STSS) in Italy was described and they have also published the draft genome of this strain. The patient was a 55-year-old male with Hodgkin's lymphoma and a previous splenectomy, who presented with severe sepsis, DIC and MOF. The isolated strain from the blood culture samples was characterized by microbiological and molecular methods: the strain was found to be serotype 2 , sequence type 1 , had a plethora of virulence genes ( $m r p, e p f, s l y, \operatorname{arcA}$, ofs type 1 and $c p s 2)$, a macrolide resistance determinant $(\mathrm{erm} \mathrm{B})$ and a rare variant of tetracycline resistance, involving efflux pumps and ribosomal protection (tet $(\mathrm{O} / \mathrm{W} / 32 / \mathrm{O})$ and tet40) [81].

S. suis infections are not uncommon but, in Western countries, infections in humans are mostly reported sporadically [15]. Unfortunately, only a few reports exist related to epidemiological data on human $S$. suis infections from European countries (corresponding to the global prevalence by $\sim 8-10 \%$ ) [1,4]. There may be a correlation between European disease epidemiology and the reality that the invasive and virulent SS2 is frequently found in pigs on the continent [82]. Interestingly, North and Central American countries (USA, Canada, Mexico, Guatemala, Costa Rica and so on) reported the lowest number of human cases, while reports on $S$. suis affecting pigs are most numerous in the United States [25]. Some suggest strains in North America belonging to SS2 to be less virulent than strains in Europe and Asia. [51]. The first publication in Europe was from Denmark [11]; nevertheless, cases have been reported from various European countries including the United Kingdom [83], Germany [84], Belgium [85], France [86], the Netherlands [87], Switzerland [88], Sweden [89], Spain [90], Portugal [91], Italy [92], Greece [93], Austria [94], Hungary [95], Croatia [96] and Serbia [97] (it must be noted that several of these reports are only available in their native languages). Most European cases of $S$. suis infections in humans were reported from the Netherlands $(n=52)$, Poland $(n=22)$, France $(n=19)$, Germany $(n=19)$, the United Kingdom $(n=19)$ and Denmark $(n=12)$, while zoonoses caused by this pathogen occurred only sporadically in the remaining countries [1,2,25,51]. Surprisingly, no cases have yet been published in Russia, the Czech Republic, Slovakia or Romania, despite the fact that the economies of the previously mentioned four countries heavily rely on animal husbandry and the production of pork meat [6]. Overall, the most prevalent clinical syndrome described in human S. suis infections is meningitis $(68.0 \%)$, followed by sepsis and toxic shock syndrome (25.0\%), arthritis (12.9\%), endocarditis (12.4\%) and endophthalmitis $(4.6 \%)[1,4,38]$. The most common corresponding clinical symptoms of infection are generally similar to those of other bacterial pyogenic meningitis, including include headache, fever, vomiting, subjective hearing impairment, positive meningeal sings, the presence of skin rash, bacteremia, shock, acute renal failure, respiratory distress, MOF, changes in the common laboratory parameters (leukocytes, platelets, C-reactive protein) and findings in the CSF $[1,4,38,51-53]$. The onset of the disease is usually 1-4 days from coming in contact with the pathogen, and depending on the disease manifestation, the duration of illness may range between 1 and 24 days. If the patient is admitted, the length of their hospital stay is usually around two weeks (range: $1-46$ days) [1,2,4,38]. The therapeutic approach of invasive S. suis infections is similar to those for other causes of bacterial meningitis/sepsis. Empiric antibiotic therapy (ceftriaxone \pm vancomycin) should be initiated without delay, which must be re-evaluated after susceptibility-testing results become available $[1,4,15,38]$. Several case reports highlighted advantageous clinical outcomes and lower chance of hearing impairment if adjunctive dexamethazone is administered to the patients. In severe cases, renal replacement therapy, assisted ventilation and circulatory support must also be provided. Among recovered patients, 39\% (31.0-47.8\%) experience hearing loss, which is sensineural and affects the high frequency range; in $~ 75 \%$ of these cases, the hearing loss is irreversible $[1,4,38,51-53]$. Twenty-three percent (15.6-32.0\%) of patients are also affected by vestibular dysfunction, which also significantly affects the quality of life of the individual [38].The low number of published human cases in these countries is presumably due to underdiagnosis and unawareness of the disease because the organism is often misidentified by microbiologists, which results in delay or inadequate treatment [25]. Misidentification may be very common in case of these bacteria; $S$. suis is frequently misidentified as S. viridans, while inappropriate results as S. bovis, S. pneumoniae, E. faecalis and S. acidominimus may 
also commonly occur $[1,2,25,51,98]$. In the case report of Tarini et al., the causative agent of meningitis for a 50 -year-old male patient was identified as $S$. mitis with a $99 \%$ probability (based on the VITEK 2 Compact ID/AST system), while sequencing results from cerebrospinal fluid confirmed $S$. suis as the true pathogen [99]. The increasing use of modern diagnostic tools (e.g., PCR, MALDI-TOF MS) and methods available for use directly from clinical specimens may further aid the identification biochemically inactive or unreliably-identified isolates $[100,101]$. A very recently published report by Olearo et al. showed the first imported human case of S. suis infection in Switzerland: a 45-year-old woman bought and consumed raw pork meat imported from a small local farm in Moldova $24 \mathrm{~h}$ before flying back to Geneva, Switzerland. She was admitted to the local hospital in septic shock three days after ingestion of the pork meat and S. suis strains were isolated and next identified by 16 rDNA sequencing from blood cultures. Later on, the serotyping of the S. suis strain was identified as serotype 14, based on a high-resolution melting assay. According to EUCAST breakpoint criteria, the susceptibility tests revealed multi-susceptible isolates; subsequently, empiric antibiotic therapy (ceftriaxone) was de-escalated (to penicillin G for 22 days) until the patient has left the hospital [102]. Based on sequencing analysis, this human strain is not genetically close to strains originating from swine previously isolated in the country. The strain was sequence type ST1 (PubMLST ID: 2250), which was new type from Switzerland. The average nucleotide identity of this strain was between 94.0\% and 99.9\%, when compared to previously deposited full sequences of S. suis genomes [102].

As occupational contact with pigs or pork meat is one of the principal factors to consider (pig-related occupation was noted in $\sim 38 \%$, while other contact with pigs was reported in $\sim 34 \%$ of published cases [4]), upholding the appropriate conditions of slaughterhouses is of utmost importance. Slaughterhouses are a good examples of epidemiological observatories, encompassing many aspects of the "One Health" perspective: they may be a source of infection in animals (resulting in local outbreaks and loss of income) and they have a role in facilitating zoonotic transmission from pigs to humans; thus, enforcing the compliance with national/international animal husbandry standards, environmental hygiene, cleaning and sanitation practices is crucial from a public health point of view. Continuous surveillance on $S$. suis carriage, serotype-distribution and the prevalence of associated diseases is also warranted among animals. From the human perspective, compliance with workplace regulations, the medical assessment of employees and education on workplace-related health risks is a responsibility of occupational medicine $[1,2,4,15,25,35,41,53]$. While swine-related occupancy is a well-known risk factor for human infections, interestingly, exposure to pigs or pork meat is not present in many of the published cases from European countries [1,2,15,25,41,53,81-97]. Although substantial new data on the incidence, clinical and microbiological characteristics, and risk factors for $S$. suis infection has been accumulated during recent years, there is not enough evidence to even estimate the prevalence of this infection on the continent. It was proposed that the principal transmission routes may significantly vary in Asian countries (oral transmission, through ingestion of raw meat) compared to the European region (transmission through injuries during meat processing) $[1,2,15,25,41,53,81-97]$. In fact, raw pork consumption was associated with more than four times (the reported odds ratio in the publication was 4.63) the risk of developing a S. suis infection (confidence interval: 2.94-7.29) [41]. However, in the report published by Manzin et al., a 68-year-old Italian patient developed a severe case of meningitis without having any contact with swine, other animals or any animal products; it was later discovered that the patient had an advanced-stage malignancy [103]. In most European countries, the infection rates among the exposed groups are poorly known as the diseases caused by $S$. suis are not notifiable, and only the United Kingdom and France consider S. suis infections in humans as an industrial-risk disease (affecting farmers, veterinarians, butchers, food processing workers and so on) $[1,2,15,25,53,81-97]$. While the colonization rate of $S$. suis in swine and wild boars has been extensively described (85-100\%), there are very few reports on the human colonization rate with S. suis; most studies report on the risk-group population of people handling pork meat, with the colonization rates ranging between $0-10 \%$ [1,2,15-17,23-35]. 
The aim of our present study was to assess the spatio-temporal trends of invasive $S$. suis infections in Hungary between 2002 and 2019, based on the data available from the National Bacteriological Surveillance System. This is, to date, the first comprehensive study of human S. suis infections from Hungary, as even case reports were available only from microbiology and infectious disease congresses throughout Hungary. Overall, 34 patients were affected by invasive S. suis infections throughout the 18-year-long study period. In addition, we have presented three distinct cases, which showed the plethora of possible outcomes of $S$. suis infections: a patient recovered without any long-term consequences, one patient reported hearing loss as a long-term sequelae, while a third, splenectomised young patient has died suddenly and quickly from infectious complications. The relatively low frequency ( $2-3$ cases/year) of invasive $S$. suis infections were highlighted in a period close to 20 years, despite the special characteristics of the country (being extensive consumers of alcohol and hard drinks due to several national traditions, an extensive agricultural sector which employs a relatively high proportion of the population, high levels of pork meat export and consumption). In addition, the prevalence of many underlying conditions responsible for higher risks of infections and immunosuppression (diabetes mellitus, alcoholism, smoking, obesity, cancers) are also pronounced in this country. Nevertheless, the average rate of infections was much higher than the reported prevalence in most Western European countries ( 0.35 vs. $0.01-0.10 / 100,000$ persons). The geographical distribution did not show any correlation with the population of the respective towns, where the strains were isolated; however, most of the cases originated from provincial areas. Although older male patients were more likely to be affected, overwhelming generalizations on the risk population cannot be made, as there were persons from very different backgrounds, vocations and age groups among affected patients. Global efforts to develop effective vaccinations against invasive S. suis infections need to be strengthened, both for human subjects in the risk of environmental exposure (especially splenectomized patients), both for animals to reduce the economic burden of these infections in animal husbandry $[104,105]$. Bojarska et al. published one of the only available long-term reports on the prevalence of S. suis in East-Central Europe: as a part of the activities of the National Reference Centre for Bacterial Meningitis (NRCBM) in Poland between 2000-2013, $n=21$ patients were affected by invasive S. suis infections [106]. Interestingly, during re-identification in the reference center, it was found that $48 \%$ of isolates were initially misidentified by the submitting microbiological laboratories. Most of the isolates were serotype 2, around half of the isolates were biofilm-producers and genes encoding for virulence factors (DNase, suilysin, extracellular protein factor, fibronectin-binding protein, muramidase-released protein, surface antigen one, enolase, serum opacity factor and pili) important in invasive disease were ubiquitous in these isolates. Their study concluded that the prevalence of $S$. suis diseases is most likely to be underestimated, as the country possesses a well-developed pork industry with a high output (over 10 million units) [106].

\section{Conclusions}

The results of our study highlight that clinicians and microbiologist need to be vigilant even in nonendemic areas, especially if the patients have a history of occupational hazards or having close contact with infected pigs even if they are immunocompetent. Educational efforts are needed among patients at increased infection risk, such as splenectomized patients or patients receiving immunosuppressive medication; these patients should avoid direct pig or pork contact when skin lesions-particularly on the hands-are present. During clinical situations, it is important to administer adequate therapy for patients with histories and symptoms suggestive of $S$. suis infections, even if laboratory verification of the diagnosis is not yet available or in case of negative cultures (due to previous administration of antimicrobials or misidentification). Infection prevention and control measures are currently the "best-buy" method available to control disease transmission, at least until an effective vaccine becomes available. From a public health perspective, educational campaigns on food safety could be an effective way to increase the understanding of the public regarding this illness, 
especially in regions, where there is strong association between traditional domestic pig slaughter and consumption of raw meat and meat products.

Author Contributions: M.G. and E.U. conceived and designed the study, performed data analysis and wrote and revised the manuscript. A.N. (Anita Németh), M.K., G.M., S.M., A.N. (Adrienn Nyul) and Z.Á. were involved in the diagnostic procedures and the treatment of the affected patients and data collection. A.S. and I.B. were involved in the treatment of the affected patients and provided resources for the study. Á.T. was the representative of the NBS, performed data collection and analysis. All authors approved the final version of the submitted manuscript.

Funding: M.G. was supported by the János Bolyai Research Scholarship of the Hungarian Academy of Sciences (BO/00144/20/5). M.G. would also like to acknowledge the support of the Diseases (MDPI) Travel Award 2020, ESCMID's "30 under 30" Award and the ESCMID Mentorship Programme. The APC was funded by the authors of the paper.

Conflicts of Interest: The authors declare no conflict of interest, monetary or otherwise. The authors alone are responsible for the content and writing of this article.

Data Availability: All data generated during the study are presented in this paper.

\section{References}

1. Lun, Z.R.; Wang, Q.P.; Chen, X.G.; Li, A.X.; Zhu, X.Q. Streptococcus suis: An emerging zoonotic pathogen. Lancet Infect. Dis. 2007, 7, 201-209. [CrossRef]

2. Gottschal, K.M.; Xu, J.; Lecours, M.-P.; Grenier, D.; Fittipaldi, N.; Segura, M. Streptococcus suis infections in humans: What is the prognosis for Western countries? (Part II). Clin. Microbiol. Newsl. 2010, 32, 97-102. [CrossRef]

3. Walsh, B.; Williams, A.E.; Satsangi, J. Streptococcus suis type 2: Pathogenesis and clinical disease. Rev. Med. Microbiol. 1992, 3, 65-71.

4. Huong, V.T.; Ha, N.; Huy, N.T.; Horby, P.; Nghia, H.D.; Thiem, V.D.; Zhu, X.; Hoa, N.T.; Hien, T.; Zamora, J.; et al. Epidemiology, clinical manifestations, and outcomes of Streptococcus suis infection in humans. Emerg. Infect. Dis. 2014, 20, 1105-1114. [CrossRef]

5. Tsai, H.Y.; Liao, C.H.; Liu, C.Y.; Huang, Y.T.; Teng, L.J.; Hsueh, P.R. Streptococcus suis infection in Taiwan, 2000-2011. Diagn. Microbiol. Infect. Dis. 2012, 74, 75-77. [CrossRef] [PubMed]

6. $\quad$ Wertheim, H.F.; Nguyen, H.N.; Taylor, W.; Lien, T.T.; Ngo, H.T.; Nguyen, T.Q.; Nguyen, B.N.T.; Nguyen, H.H.; Nguyen, H.M.; Nguyen, C.T.; et al. Streptococcus suis, an important cause of adult bacterial meningitis in northern Vietnam. PLoS ONE 2009, 4, e5973. [CrossRef]

7. Gottschalk, M.; Segura, M.; Xu, J. Streptococcus suis infections in humans: The Chinese experience and the situation in North America. Anim. Health Res. Rev. 2007, 8, 29-45. [CrossRef] [PubMed]

8. Field, H.I.; Buntain, D.; Done, J.T. Studies on pig mortality I. Streptococcal meningitis and arthritis. Vet. Rec. 1954, 6, 453-455.

9. Spiss, H.K.; Kofler, M.; Hausdorfer, H.; Pfausler, B.; Schmutzhard, E. Streptococcus suis meningitis and neurophysiology of the acoustic system. First case report from Austria. Nervenarzt 1999, 70, 738-741. [CrossRef] [PubMed]

10. Colaert, J.; Allewaert, M.; Magerman, H.; Vandeven, J.; Vandepitte, J. Streptococcus suis meningitis in man. First reported observation in Belgium. Acta Clin. Belg. 1985, 40, 314-317. [CrossRef]

11. Kjems, E.; Perch, B. Serious infections in man caused by group R streptococci. Ugeskr. Laeger 1975, 137, 682-683. [PubMed]

12. Chau, P.Y.; Huang, C.Y.; Kay, R. Streptococcus suis meningitis. An important underdiagnosed disease in Hong Kong. Med. J. Astr. 1983, 1, 414-417.

13. Hui, A.C.; Ng, K.C.; Tong, P.Y.; Mok, V.; Chow, K.M.; Wu, A.; Wong, L.K.S. Bacterial meningitis in Hong Kong: 10-years' experience. Clin. Neurol. Neurosurg. 2005, 107, 366-370. [CrossRef] [PubMed]

14. Navacharoen, N.; Chantharochavong, V.; Hanprasertpong, C.; Kangsanarak, J.; Lekagul, S. Hearing and vestibular loss in Streptococcus suis infection from swine and traditional raw pork exposure in northern Thailand. J. Laryngol. Otol. 2009, 123, 857-862. [CrossRef] [PubMed]

15. Ágoston, Z.; Terhes, G.; Hannauer, P.; Gajdács, M.; Urbán, E. Fatal case of bacteremia caused by Streptococcus suis in a splenectomized man and a review of the European literature. Acta Microbiol. Immunol. Hung. 2020. [CrossRef] 
16. Cammaert, T.; Verstraete, W.; Baeck, E. Deafness-blindness caused by Streptococcus suis meningitisEpidemiology and rehabilitation. Acta Otorhinolaryngol. Belg. 1990, 44, 37-41.

17. Okura, M.; Osaki, M.; Nomoto, R.; Arai, S.; Osawa, R.; Tsutomu, S.; Takamatsu, D. Current Taxonomical Situation of Streptococcus suis. Pathogens 2016, 5, 45. [CrossRef]

18. Fittipaldi, N.; Segura, M.; Greiner, D.; Gottschalk, M. Virulence factors involved in the pathogenesis of the infection caused by the swine pathogen and zoonotic agent Streptococcus suis. Future Microbiol. 2012, 7, 259-279. [CrossRef]

19. Willemse, N.; van der Ark, K.C.H.; Stockhofe-Zurwieden, N.; Smith, H.; Picavet, D.I.; Solt-Smits, C.; Wisselink, H.J.; Schultsz, C.; de Greef, A. Clonal expansion of a virulent Streptococcus suis serotype 9 lineage distinguishable from carriage subpopulations. Sci. Rep. 2019, 9, e15429. [CrossRef]

20. Li, G.; Lu, G.; Qi, Z.; Li, H.; Wang, L.; Wang, Y.; Liu, B.; Niu, X.; Deng, X.; Wang, J. Morin Attenuates Streptococcus suis Pathogenicity in Mice by Neutralizing Suilysin Activity. Front. Microbiol. 2017, 8, e460. [CrossRef]

21. Vötsch, D.; Willenborg, M.; Weldeargay, Y.B.; Valentin-Weigan, P. Streptococcus suis—The "Two Faces" of a Pathobiont in the Porcine Respiratory Tract. Front. Microbiol. 2018, 9, e480. [CrossRef] [PubMed]

22. Baums, C.G.; Kaim, U.; Fulde, M.; Ramachandran, G.; Goethe, R.; Valentin-Weingard, P. Identification of a Novel Virulence Determinant with Serum Opacification Activity in Streptococcus suis. Infect. Immun. 2006, 74, 6154-6162. [CrossRef]

23. Smith, H.E.; Veenbergen, V.; van der Velde, J.; Damman, M.; Wisselink, H.J.; Smits, M.A. The cps Genes of Streptococcus suis Serotypes 1, 2, and 9: Development of Rapid Serotype-Specific PCR Assays. J. Clin. Microbiol. 1999, 37, 3146-3152. [CrossRef] [PubMed]

24. Zheng, H.; Qiu, X.; Roy, D.; Segura, M.; Du, P.; Xu, J.; Gottschalk, M. Genotyping and investigating capsular polysaccharide synthesis gene loci of non-serotypeable Streptococcus suis isolated from diseased pigs in Canada. Vet. Res. 2017, 48, e10. [CrossRef] [PubMed]

25. Goyette-Desjardins, G.; Auger, J.P.; Xu, J.; Segura, M.; Gottschalk, M. Streptococcus suis, an important pig pathogen and emerging zoonotic agent-an update on the worldwide distribution based on serotyping and sequence typing. Emerg. Microbes Infect. 2014, 3, e45. [CrossRef] [PubMed]

26. Athey, T.B.T.; Auger, J.P.; Teatero, S.; Dumesnil, A.; Takamatsu, D.; Wassercheid, J.; Dewar, K.; Gottschalk, M.; Fittpaldi, N. Complex Population Structure and Virulence Differences among Serotype 2 Streptococcus suis Strains Belonging to Sequence Type 28. PLoS ONE 2015, 10, e0137760. [CrossRef] [PubMed]

27. Athey, T.B.T.; Teatero, S.; Lacouture, S.; Takamatsu, D.; Gottschalk, M.; Fittipaldi, N. Determining Streptococcus suis serotype from short-read whole-genome sequencing data. BMC Microbiol. 2016, 16, e162. [CrossRef] [PubMed]

28. Van Calsteren, M.R.; Gangon, F.; Calzas, C.; Goyette-Desjardins, G.; Okura, M.; Takamatsu, D.; Gottschalk, M.; Segura, M. Structure determination of Streptococcus suis serotype 14 capsular polysaccharide. Biochem. Cell. Biol. 2013, 91, 49-58. [CrossRef]

29. Lowe, B.A.; Marsh, T.L.; Isaacs-Cosgrove, N.; Kirkwood, R.N.; Kiupel, M.; Mulks, M.H. Microbial communities in the tonsils of healthy pigs. Vet. Microbiol. 2011, 147, 346-357. [CrossRef]

30. Taniyama, D.; Sakurai, M.; Sakai, T.; Kikuchi, T.; Takahashi, T. Human case of bacteremia due to Streptococcus suis serotype 5 in Japan: The first report and literature review. IDCases 2016, 6, 36-38. [CrossRef]

31. Hatrongjit, R.; Kerdsin, A.; Gottschalk, M.; Takeuchi, D.; Hamada, S.; Oishi, K.; Akeda, Y. First human case report of sepsis due to infection with Streptococcus suis serotype 31 in Thailand. BMC Infect. Dis. 2015, 15, 392. [CrossRef] [PubMed]

32. Gustavsson, C.; Rasmussen, M. Septic arthritis caused by Streptococcus suis serotype 5 in pig farmer. Emerg. Infect. Dis. 2014, 20, 489-490. [CrossRef] [PubMed]

33. Callejo, R.; Prieto, M.; Salamone, F.; Auger, J.P.; Goyette-Desjardins, G.; Gottschalk, M. Atypical Streptococcus suis in man, Argentina, 2013. Emerg. Infect. Dis. 2014, 20, 500-502. [CrossRef]

34. Kerdsin, A.; Gottschalk, M.; Hatrongjit, R.; Hamada, S.; Akeda, Y.; Oishi, K. Fatal septic meningitis in child caused by Streptococcus suis serotype 24. Emerg. Infect. Dis. 2016, 22, 1519-1520. [CrossRef] [PubMed]

35. Nghia, H.D.; Hoa, N.T.; Linh, D.; Campbell, J.; Diep, T.S.; Chau, N.V.; Mai, T.H.; Hien, T.T.; Spratt, B.; Farrar, J.; et al. Human case of Streptococcus suis serotype 16 infection. Emerg. Infect. Dis. 2008, 14, 155-157. [CrossRef] 
36. Chen, C.; Tang, J.; Dong, W.; Wang, C.; Feng, Y.; Zheng, F.; Pan, X.; Liu, D.; Li, M.; Song, Y.; et al. A glimpse of streptococcal toxic shock syndrome from comparative genomics of S. suis 2 Chinese isolates. PLoS ONE 2007, 2, e315. [CrossRef]

37. Wangsomboonsiri, W.; Luksanaun, T.; Saksornchai, S.; Ketwong, K.; Sungkanuparph, S. Streptococcus suis infection and risk factors for mortality. J. Infect. 2008, 57, 392-396. [CrossRef]

38. Hughes, J.M.; Wilson, M.E.; Wertheim, H.F.L.; Nghia, H.D.T.; Taylor, W.; Schultsz, C. Streptococcus suis: An Emerging Human Pathogen. Clin. Infect. Dis. 2009, 48, 617-625.

39. Callejo, R.; Zheng, H.; Du, P.; Prieto, M.; Xu, J.; Zielinski, G.; Auger, J.P.; Gottschalk, M. Streptococcus suis serotype 2 strains isolated in Argentina (South America) are different from those recovered in North America and present a higher risk for humans. JMM Case Rep. 2016, 3, e005066. [CrossRef]

40. Papatsiros, V.G.; Vourvidis, D.; Tzitzis, A.A.; Meichanetsidis, P.S.; Stougiou, D.; Mintza, D.; Papaionannou, P.S. Streptococcus suis: An important zoonotic pathogen for human-Prevention aspects. Vet. World 2011, 4, 216-221. [CrossRef]

41. Rayanakorn, A.; Katip, W.; Goh, B.H.; Oberdorfer, P.; Lee, L.H. Clinical Manifestations and Risk Factors of Streptococcus suis Mortality Among Northern Thai Population: Retrospective 13-Year Cohort Study. Infect. Drug Res. 2019, 12, 3955-3965. [CrossRef] [PubMed]

42. Gómez-Zorrilla, S.; Ardanuy, C.; Lora-Tamayo, J.; Cámara, J.; Garcia-Somoza, D.; Pena, C.; Ariza, J. Streptococcus suis Infection and Malignancy in Man, Spain. Emerg. Infect. Dis. 2014, 20, 1067-1068. [CrossRef] [PubMed]

43. Elbers, A.R.; Vecht, U.; Osterhaus, A.D.; Groen, J.; Wisselink, H.J.; Diepersloot, R.J.; Tielen, M.J.M. Low prevalence of antibodies against the zoonotic agents Brucella abortus, Leptospira spp., Streptococcus suis serotype II, hantavirus, and lymphocytic choriomeningitis virus among veterinarians and pig farmers in the southern part of The Netherlands. Vet. Q. 1999, 21, 50-54. [CrossRef] [PubMed]

44. Smith, T.C.; Capuano, A.W.; Boese, B.; Myers, K.P.; Gray, G.C. Exposure to Streptococcus suis among US swine workers. Emerg. Infect. Dis. 2008, 14, 1925-1927. [CrossRef]

45. Arends, J.P.; Zanen, H.C. Meningitis caused by Streptococcus suis in humans. Rev. Infect. Dis. 1988, 10, 131-137. [CrossRef]

46. Segura, M.; Gottschalk, M. Streptococcus suis interactions with the murine macrophage cell line J774: Adhesion and cytotoxicity. Infect. Immun. 2002, 70, 4312-4322. [CrossRef]

47. Auger, J.P.; Gottschalk, M. The Streptococcus suis factor H-binding protein: A key to unlocking the blood-brain barrier and access the central nervous system? Virulence 2017, 8, 1081-1084. [CrossRef]

48. Vanier, G.; Segura, M.; Firedl, P.; Lacouture, S.; Gottschalk, M. Invasion of porcine brain microvascular endothelial cells by Streptococcus suis serotype 2. Infect. Immun. 2004, 72, 1441-1449. [CrossRef]

49. Xia, X.; Qin, W.; Zhu, H.; Wang, X.; Jiang, J.; Hu, J. How Streptococcus suis serotype 2 attempts to avoid attack by host immune defenses. J. Microbiol. Immunol. Infect. 2019, 52, 516-525. [CrossRef]

50. King, S.J.; Leigh, J.A.; Heath, P.J.; Luque, I.; Tarradas, C.; Dowson, C.G.; Whatmore, A.M. Development of a multilocus sequence typing scheme for the pig pathogen Streptococcus suis: Identification of virulent clones and potential capsular serotype exchange. J. Clin. Microbiol. 2002, 40, 3671-3680. [CrossRef]

51. Lachance, C.; Gottschalk, M.; Gerber, P.P.; Lemire, P.; Xu, J.; Segura, M. Exacerbated type II interferon response drives hypervirulence and toxic shock by an emergent epidemic strain of Streptococcus suis. Infect. Immun. 2013, 81, 1928-1939. [CrossRef] [PubMed]

52. Besung, N.K.I.; Suarjana, K.G.I.; Agusta, K.K.; Winaya, I.B.O.; Soesharsono, H.; Suwiti, K.T.; Mahardika, G.N. Isolation and identification of Streptococcus suis from sick pigs in Bali, Indonesia. BMC Res. Notes 2019, 12, e795. [CrossRef] [PubMed]

53. Doto, D.S.; Moreno, L.Z.; Calderaro, F.F.; Matajira, C.E.; de Moura, G.T.V.; Ferrerira, T.S.; Mesquita, R.E.; Timenetsky, J.; Gottschalk, M.; Moreno, M.A. Genetic diversity of Streptococcus suis serotype 2 isolated from pigs in Brazil. Can. J. Vet. Res. 2016, 80, 106-111. [PubMed]

54. Hungarian Central Statistical Office. Demographic Data. Available online: http://www.ksh.hu/nepszamlalas/ tablak_demografia (accessed on 24 July 2020).

55. Organisation for Economic Co-Operation and Development. Country Summary: Hungary. Available online: https://www.oecd.org/hungary/publicationsdocuments/reports/ (accessed on 24 July 2020).

56. Hungarian Central Statistical Office. Medical Statistics. Available online: https://www.ksh.hu/docs/hun/ xstadat/xstadat_hosszu/h_fea001.html (accessed on 24 July 2020). 
57. Hungarian Central Statistical Office. Gazetteer of Hungary. Available online: https://www.ksh.hu/docs/hun/ hnk/hnk_2019.pdf (accessed on 24 July 2020).

58. WHO Global Status Report on Alcohol and Health. Available online: https://www.who.int/substance_abuse/ publications/global_alcohol_report/msbgsruprofiles.pdf (accessed on 24 July 2020).

59. Hungarian Central Statistical Office. Agricultural Statistical Data. Available online: https://www.ksh.hu/ agricultural_census_long_time_series (accessed on 24 July 2020).

60. Adamowksi, J. Hungary Aims for $12 \%$ Pork Consumption Increase. Available online: https://www. foodnavigator.com/Article/2013/12/16/Hungary-aims-for-12-pork-consumption-increase (accessed on 24 July 2020).

61. National Bacteriological Surveillance Management Team. NBS Annual Reports, 2002-2019. National Institute of Environmental Health. Budapest, Hungary. Available online: www.oek.hu (accessed on 24 July 2020).

62. Nagy, E.; Ábrók, M.; Bartha, N.; Bereczki, L.; Juhász, E.; Kardos, G.; Kristóf, J.; Miszti, C.; Urbán, E. Special application of matrix-assisted laser desorption ionization time-of-flight mass spectrometry in clinical microbiological diagnostics. Orv. Hetil. 2014, 155, 1495-1503. [CrossRef]

63. Gajdács, M.; Urbán, E. The relevance of anaerobic bacteria in brain abscesses: A ten-year retrospective analysis (2008-2017). Infect. Dis. 2019, 51, 779-781. [CrossRef]

64. Gajdács, M.; Urbán, E. Epidemiology and resistance trends of Staphylococcus aureus isolated from vaginal samples: A 10-year retrospective study in Hungary. Acta Dermatovenerol. Alp. Pannonica Adriat. 2019, 28, 143-147. [CrossRef]

65. Voutsadakis, I.A. Streptococcus suis endocarditis and colon carcinoma: A case report. Clin. Colorectal Cancer 2006, 6, 226-228. [CrossRef]

66. Arends, J.P.; Hartwig, N.; Rudolphy, M.; Zanen, H.C. Carrier rate of Streptococcus suis capsular type 2 in palatine tonsils of slaughtered pigs. J. Clin. Microbiol. 1984, 20, 945-947. [CrossRef]

67. Bonmarchand, G.; Massari, P.; Humbert, G.; Leroy, J.; Morel, A.; Lemeland, J.F.; Vannie, P. Group R streptococci: Wild boars as a second reservoir. Scand. J. Infect. Dis. 1985, 17, 121-122. [CrossRef]

68. Pallarés, F.J.; Halbur, P.G.; Schmitt, C.S.; Roth, J.A.; Opriessnig, T.; Thomas, P.J.; Kinyon, J.M.; Murphy, D.; Frank, D.A.; Hoffman, L.J. of experimental models for Streptococcus suis infection of conventional pigs. Can. J. Vet. Res. 2003, 67, 225-228.

69. Segura, M.; Calzas, C.; Greiner, D.; Gottschalk, M. Initial steps of the pathogenesis of the infection caused by Streptococcus suis: Fighting against nonspecific defenses. FEBS Lett. 2016, 591, 3772-3799. [CrossRef]

70. CORDIS Program for Innovative Global Prevention of Streptococcus suis. Available online: https://cordis. europa.eu/project/id/727966 (accessed on 24 July 2020).

71. WHO: Outbreak Associated with Streptococcus suis in Pigs in China: Update. Available online: https: //www.who.int/zoonoses/outbreaks/zoonosesoutbreaksuis1/en/ (accessed on 24 July 2020).

72. Del'Arco, A.E.; Santos, J.L.; Bevilacqua, P.D.; Faria, J.E.; Guimaraes, W.V. Swine infection by Streptococcus suis: A retrospective study Arq. Bras. Med. Vet. Zootec. 2008, 60, 878-883. [CrossRef]

73. Koldkjaer, O.; Nielsen, G. Haemolytic Streptococcus group R infection. Br. Med. J. 1972, 3, 765. [CrossRef]

74. Watkins, E.J.; Brooksby, P.; Schweiger, M.S.; Enright, S.M. Septicaemia in a pig-farm worker. Lancet 2001, 357, 38. [CrossRef]

75. Rayanakorn, A.; Katip, W.; Goh, B.H.; Oberdorfer, P.; Lee, L.H. A risk scoring system for predicting Streptococcus suis hearing loss: A 13-year retrospective cohort study. PLoS ONE 2020, 15, e0228488. [CrossRef]

76. Esteves, S.S.; de Almeida, J.C.; Abrunhosa, J.; Sousa, C.A.; Arshad, Q. Pig's ear: Streptococcus suis Meningitis and its associated inner ear implications. IDCases 2017, 10, 55-57. [CrossRef]

77. Huh, H.J.; Park, K.J.; Jang, J.H.; Lee, M.; Lee, J.H.; Ahn, Y.H.; Kang, C.I.; Ki, C.S.; Lee, N.Y. Streptococcus suis Meningitis with Bilateral Sensorineural Hearing Loss. Korean J. Lab. Med. 2011, 31, 205-211. [CrossRef]

78. Staats, J.J.; Feder, I.; Okwumabua, O.; Chengappa, M.M. Streptococcus Suis: Past and Present. Vet. Res. Commun. 1997, 21, 381-407. [CrossRef]

79. Charland, N.; Kobisch, M.; Martineau-Doizé, B.; Jacques, M.; Gottschalk, M. Role of capsular sialic acid in virulence and resistance to phagocytosis of Streptococcus suis capsular type 2. Pathogens Dis. 1996, 14, 195-203.

80. Feng, Y.; Zhang, H.; Wu, Z.; Wang, S.; Cao, M.; Hu, D.; Wang, C. Streptococcus suis infection: An emerging/ reemerging challenge of bacterial infectious diseases? Virulence 2014, 5, 477-497. [CrossRef] 
81. Mancini, F.; Adamo, F.; Creti, R.; Monaco, M.; Alfarone, G.; Pantosti, A.; Ciervo, A. A fatal case of streptococcal toxic shock syndrome caused by Streptococcus suis carrying tet $(40)$ and tet $(\mathrm{O} / \mathrm{W} / 32 / \mathrm{O})$, Italy. J. Infect. Chemother. 2016, 22, 774-776. [CrossRef]

82. Wisselink, H.J.; Smith, H.E.; Stockhofe-Zurwieden, N.; Peperkamp, K.; Vecht, U. Distribution of capsular types and production of muramidase-released protein (MRP) and extracellular factor (EF) of Streptococcus suis strains isolated from diseased pigs in seven European countries. Vet. Microbiol. 2000, 74, 237-248. [CrossRef]

83. Perch, B.; Kjems, E. Group R Streptococcus infections in man. JAMA 1971, 216, 1484. [CrossRef] [PubMed]

84. Rosenkranz, M.; Elsner, H.A.; Sturenburg, H.J.; Weiller, C.; Rother, J.; Sobottka, I. Streptococcus suis meningitis and septicemia contracted from a wild boar in Germany. J. Neurol. 2003, 250, 869-870. [CrossRef] [PubMed]

85. Hantson, P.; Vekemans, M.C.; Gauiter, P.; Mahieu, P.; Sindic, J.C.; Guerit, J.M.; Wauters, G.; Nannan, M. Fatal Streptococcus suis meningitis in man. Acta Neurol. Belg. 1999, 91, 165-168.

86. Paul, G.; Ancelle, J.P.; Lionsquy, G.; Brochard, C.; Brassac, R.; Nevot, P. Human meningitis by group R Streptococcus: An unknown anthropozoonosis? Med. Mal. Infect. 1977, 7, 525-529. [CrossRef]

87. van de Beek, D.; Spanjaard, L.; de Gans, J. Streptococcus suis meningitis in the Netherlands. J. Infect. 2008, 57, 158-161. [CrossRef]

88. Stevens, M.J.A.; Serrano, N.S.; Cernela, N.; Schmitt, S.; Schernzel, J.; Stephan, R. Massive Diversity in Whole-Genome Sequences of Streptococcus suis Strains from Infected Pigs in Switzerland. Microbiol. Res. Announ. 2019, 8, e01656-18. [CrossRef]

89. Perch, B.; Kristjansen, P.; Skadhauge, K. Group R streptococci pathogenic for man. Two cases of meningitis and one fatal case of sepsis. Acta Pathol. Microbiol. Scand. 1968, 74, 69-76. [CrossRef]

90. Aspiroz, C.; Vela, A.I.; Pascual, M.S.; Aldea, M.J. Acute infective endocarditis due to Streptococcus suis serotype 2 in Spain. Enferm. Infecc. Microbiol. Clin. 2009, 27, 370-371. [CrossRef]

91. Taipa, R.; Lopes, V.; Magalhaes, M. Streptococcus suis meningitis: First case report from Portugal. J. Infect. 2008, 56, 482-483. [CrossRef] [PubMed]

92. Camporese, A.; Tizianel, G.; Bruschetta, G.; Cruciatti, B.; Pomes, A. Human meningitis caused by Streptococcus suis: The first case report from north-eastern Italy. Infez Med. 2007, 15, 111-114. [PubMed]

93. Mazokopakis, E.E.; Kofteridis, D.P.; Papadakis, J.A.; Gikas, A.H.; Samonis, G.J. First case report of Streptococcus suis septicaemia and meningitis from Greece. Eur. J. Neurol. 2005, 12, 487-489. [CrossRef] [PubMed]

94. Willemse, N.; Howell, K.J.; Weinert, L.A.; Heuvelink, A.; Pannekoek, Y.; Wagenaar, J.A.; Smith, H.E.; van der Ende, A.; Schultsz, C. An emerging zoonotic clone in the Netherlands provides clues to virulence and zoonotic potential of Streptococcus suis. Sci Rep. 2016, 6, e28984. [CrossRef] [PubMed]

95. Németh, A.; Knausz, M.; Schmidt, P. Special case of purulent meningitis caused by Streptococcus suis. Case report. Orv. Hetil. 2019, 160, 30-34. [CrossRef]

96. Kopic, J.; Paradzik, M.T.; Pandak, N. Streptococcus suis infection as a cause of severe illness: 2 cases from Croatia. Scand. J. Infect. Dis. 2002, 34, 683-684. [CrossRef]

97. Stanojković, A.; Petrović, M.M.; Škrbić, Z.; Mandić, V.; Stanišić, N.; Gogić, M.; Stanojković-Sebić, A. Biochemical characteristics of Streptococcus suis strains isolated from healthy and deceased pigs. Biotechnol. Anim. Husb. 2014, 30, 699-704. [CrossRef]

98. Tsai, H.C.; Lee, S.S.; Wann, S.R.; Huang, T.S.; Chen, Y.S.; Liu, Y.C. Streptococcus suis meningitis with ventriculoperitoneal shunt infection and spondylodiscitis. J. Formos. Med. Assoc. 2005, 104, 948-950.

99. Tarini, N.M.A.; Setiabudy, M.; Susilawathi, N.M.; Fatmawati, N.; Mayura, I.; Darwinata, E.A.; Sudiariani, N.K.A. Misidentification of S. suis as a Zoonotic Agent. Maced. J. Med. Sci. 2019, 25, 2309-2312. [CrossRef]

100. Feucherolles, M.; Poppert, S.; Utzinger, J.; Becker, S.L. MALDI-TOF mass spectrometry as a diagnostic tool in human and veterinary helminthology: A systematic review. Parasites Vectors 2019, 12, e245. [CrossRef]

101. Kostrzewa, M.; Nagy, E.; Schrötter, P.; Pranada, A.B. How MALDI-TOF mass spectrometry can aid the diagnosis of hard-to-identify pathogenic bacteria-The rare and the unknown. Expert Rev. Mol. Diagn. 2019, 19, 667-682. [CrossRef] [PubMed]

102. Olearo, F.; Marinosci, A.; Stephan, R.; Cherkaoui, A.; Renzi, G.; Gaia, N.; Leo, S.; Lazarevic, V.; Schrenzel, J. First case of Streptococcus suis infection in Switzerland: An emerging public health problem? Travel Med. Infect. Dis. 2020, e101590. [CrossRef] [PubMed] 
103. Manzin, A.; Palmieri, C.; Serra, C.; Saddi, B.; Princivalli, M.S.; Lou, G.; Angioni, G.; Tiddia, F.; Valdaro, P.E.; Facineli, B. Streptococcus suis meningitis without history of animal contact, Italy. Emerg. Infect. Dis. 2008, 14, 1946-1948. [CrossRef]

104. Baums, C.G.; Kock, C.; Beineke, A.; Bennecke, K.; Goethe, R.; Schröder, C.; Waldmann, K.H.; Valentin-Weigand, P. Streptococcus suis Bacterin and Subunit Vaccine Immunogenicities and Protective Efficacies against Serotypes 2 and 9. Clin. Vaccine Immunol. 2009, 16, 200-208. [CrossRef] [PubMed]

105. Segura, M. Streptococcus suis vaccines: Candidate antigens and progress- Expert. Rev. Vaccines 2015, 14, 1587-1608. [CrossRef] [PubMed]

106. Bojarska, A.; Molska, E.; Janas, K.; Skoczynska, A.; Stefaniuk, E.; Hryniewicz, W.; Sadowy, E. Streptococcus suis in invasive human infections in Poland: Clonality and determinants of virulence and antimicrobial resistance. Eur. J. Clin. Microbiol. Infect. Dis. 2016, 35, 917-925. [CrossRef]

(C) 2020 by the authors. Licensee MDPI, Basel, Switzerland. This article is an open access article distributed under the terms and conditions of the Creative Commons Attribution (CC BY) license (http://creativecommons.org/licenses/by/4.0/). 